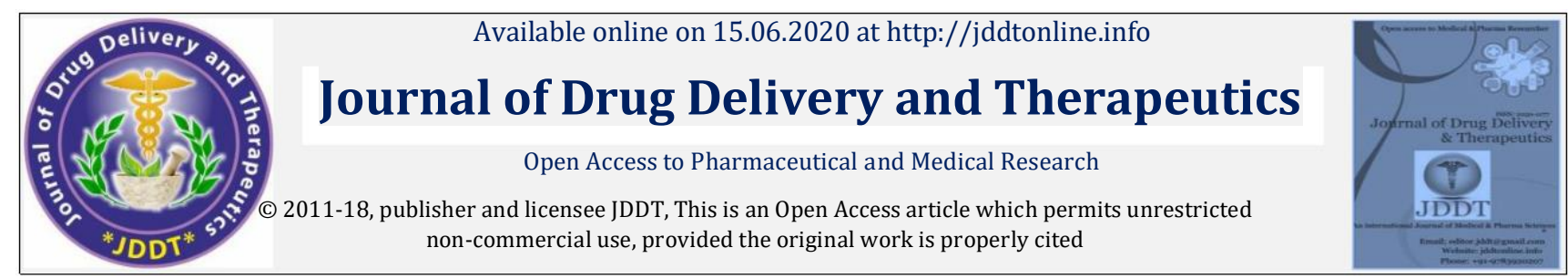

Open $\odot$ Access

\title{
Budgetary Impact of Covering "Me-Too" Drugs from Social Security: Buenos Aires State Case Report
}

\author{
Gustavo H. Marin 1,2, Lupe Marin 1,3, Daniel Agüero 4, Gina Marin 1, Mariana Pagnotta 1,5, Luis Blanco 1 \\ 1. Faculty of Medical Science. National University of La Plata, Argentina \\ 2. CONICET : National Scientific and Technical Research Council, Argentina \\ 3. CIC: Scientific Research Committee, Buenos Aires, Argentina \\ 4. National University of Arturo Jauretche, Fcio.Varela, Argentina \\ 5. Buenos Aires State Medical and Social Security, Argentina
}

\section{ABSTRACT}

The majority of new drugs registered at Health Global Market are not considered real innovations and due to their chemical structure similarity of reference's group drug, they are known as "me-too". These "me too" drugs usually has no additional therapeutic benefits but greatly increasing treatment cost. PURPOSE: To demonstrate the economic impact in Social Security budget by covering "me too" medicines. METHODS: An epidemiological-descriptive-analytical study was performed in order to analyze the burden of anti-hypertensive prescription from patients under coverage by Buenos Aires State Social Security (SS). Two types of medicines were compared: "pioneer/classic" or "me-too". Variables considered were: medicine type, therapeutical group, global costs, burden for SS and for patients. RESULTS: From 185865 patients with hypertension treated; in 121748 of the cases the strategy was monotherapy while 64117 of them received at least two or more medicines. 189714 were reference drugs while 64393 were considered "me-too". In average, "me-too" drugs were $41.23 \%$ more expensive than classical treatment. The percentage covered by SS varies according to the medicines (between 45 to $51 \%$ ) and patients must complete the amount of money remaining from their pockets. Paradoxically, the percentage covered by SS of some "me-too" were greater than coverage for most classic medications of each group. CONCLUSIONS: By only choosing the drug of reference from each therapeutical group with has proven effectiveness, the Social Security might increase the coverage to $100 \%$ of the cost of all anti-hypertensive treatment for all patients; and even that, still saving almost 2 million dollars per year.

Keywords: Health, Policies, Medicines, Me too, Economical Burden, Coverage, anti-hypertensive

Article Info: Received 09 April 2020; $\quad$ Review Completed 22 May 2020; Accepted 02 June 2020; $\quad$ Available online 15 June 2020

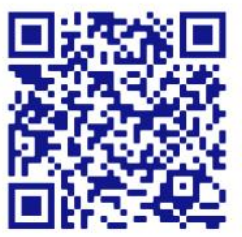

Cite this article as:

Marin GH, Marin L, Agüero D, Pagnotta M, Marin G, Blanco L, Budgetary Impact of Covering “Me-Too" Drugs from Social Security: Buenos Aires State Case Report, Journal of Drug Delivery and Therapeutics. 2020; 10(3-s):234-238 http://dx.doi.org/10.22270/jddt.v10i3-s.4087

Gustavo H. Marin, National University of La Plata, Calle 60 y 120, (1900) La Plata, Argentina

\section{INTRODUCTION}

Pharmacological treatments became an important component of Health systems budgets, especially for the known as "high-cost medicines" that have captured the attention of health funders and are worrying health systems all over the world because of their risk of an economic bankruptcy 1.

However, little has been focused on medicines that, although less expensive, could have a negative impact for the public finances of the health systems. This is the case of a group of medicines known as "me-too"2. Concerning this type of drugs, it could be said that the pharmaceutical industry makes an investment to develop medicines with identical mechanisms of action to a pioneer/reference pre-existing drug from same therapeutical group, which has already proven to be an efficient treatment 3. It could then be argued that this type of drugs would be valuable to payers if they save costs 4 . However, this situation is generally the reverse, since when a new therapeutic option appears in the market, it has a higher cost than the drugs previously available in the pharmacy 5.

This situation occurs because, once these "me too" drugs are marketed, they must be installed among prescribers and patients, through promotional spending, delivery of free medical samples, initial price discounts, advertisements, events and conferences, all elements that are associated with large expenses that will be recovered once the new drug is installed among patients and doctors in order to potentially replace the pre-existing drug of the class group 6. 
The problem is that this new drug is always placed the pharmaceutical market at a higher price than the reference medicine, increasing costs for both patients and the health systems 7. But the impact in the budgets of developing countries of the inclusion of these me-too drugs in their official list of medicines to be cover by public funders, is still uncertain 8 .

It is the purpose of this paper to determine the economic impact, for the Buenos Aires State Social Security (SS), of financing "me-too" drugs and to calculate the potential save of replacement the "me-too" option by the pioneer/ reference drug in each therapeutical group that already have demonstrated its efficacy, its safety and its suitability to treat a highly prevalent chronic disease like hypertension.

\section{METHODS}

\section{Type of study}

The present work should be classified as an epidemiologicaldescriptive study with an analytical stage.

\section{Population}

Patients enrolled for this study were Buenos Aires State Social Security beneficiaries nucleated in IOMA (BA State SS), affected by hypertension disease that required pharmacological treatment.

\section{Inclusion and Exclusion Criteria of patients to the study}

For the present study, authors adopted the recommendations of the Eighth Joint National Committee for diagnosis and treat-ment of hypertension disease, in order to enroll patients in the analysis.
Exclusion criteria were patients hospitalized at the time while the study was initiated, or patients were severe hypertension disease that need intravenous treatment.

\section{Period of study}

$$
\text { 01/01/2017 to } 31 / 12 / 2017
$$

\section{Cost evaluation}

The cost of the medicines was considered as defined daily dose (DDD) for each patient treated. The prescription and drug delivery were extracted from SS annual ambulatory data-base.

\section{Statistical analysis}

In order to analyze the statistical significance of the experimental results between the different groups, the nonparametric ANOVA test was used, provided $p<0.05$ as the limit of significance.

\section{RESULTS}

The number of patients with hypertension that demand coverage of treatment to the State Social Security IOMA during the period of study were 185865 patients; 121748 of them received only one anti-hypertensive drug while 64117 received at least two or more medicines. The patient's adherence to anti-hypertensive treatment was $40.5 \%$ in average for all medicines. Almost twenty different drugs were prescript in order to treat patients under SS-IOMA coverage (Figure 1).

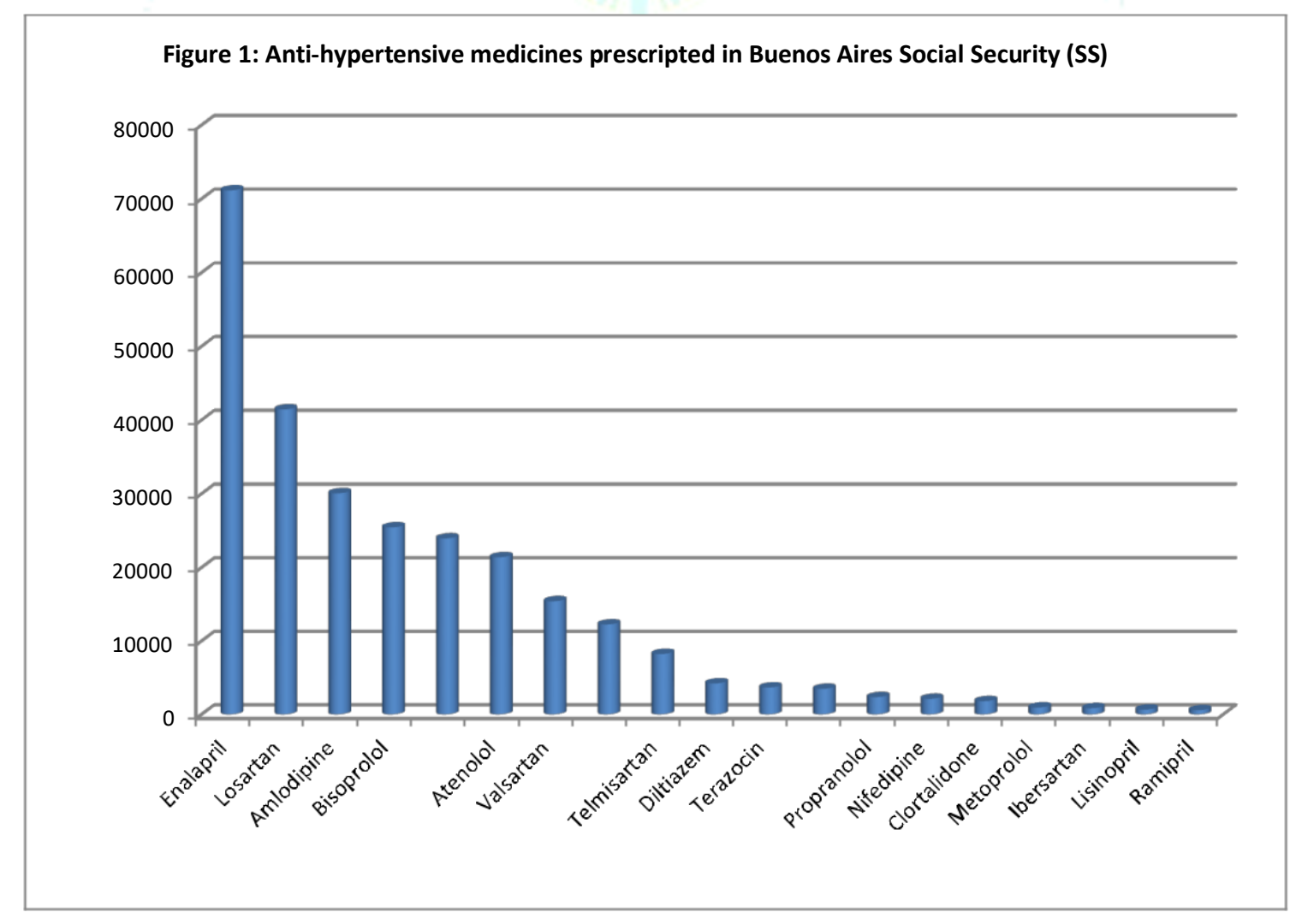

Figure 1: Anti-hypertensive medicines prescripted in Buenos Aires Social Security (SS) 
While 189714 of the drugs prescript were pioneer/reference drugs, 64393 were classified as "me-too".
The description of the drug covered by SS is exposed in Table 1.

\begin{tabular}{|c|c|c|c|c|c|c|}
\hline \multicolumn{7}{|c|}{ Table 1: Characteristics of anti-hypertensive drugs covered } \\
\hline \multicolumn{2}{|c|}{ Therapeutic Group } & Drug & $\begin{array}{c}\text { No } \\
\text { patient } \\
\text { treated }\end{array}$ & \begin{tabular}{|c|} 
Mean \\
Price in \\
Argentine \\
market
\end{tabular} & $\begin{array}{l}\text { Expenses } \\
\text { for IOMA }\end{array}$ & $\begin{array}{c}\% \text { de } \\
\text { covered }\end{array}$ \\
\hline \multirow{6}{*}{ 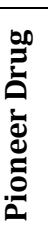 } & ACE inhibitor & Enalapril & 71145 & 134.80 & 66.00 & 48.9 \\
\hline & Beta Blockers & Atenolol & 21392 & 206.80 & 77.37 & 37.4 \\
\hline & Angiotensin & Losartan & 41437 & 357.10 & 246.00 & 68.9 \\
\hline & Calcium Blockers & Amlodipine & 30053 & 194.97 & 99.60 & 51.1 \\
\hline & Diuretics & HClthiazide & 23932 & 123.53 & 78.00 & 63.1 \\
\hline & & Clortalidone & 1782 & 59.94 & 22.64 & 37.7 \\
\hline \multirow{13}{*}{ 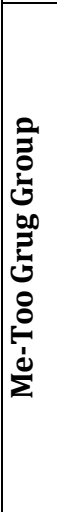 } & ACE inhibitor & Lisinopril & 637 & 296.94 & 102.94 & 34.6 \\
\hline & & Ramipril & 552 & 374.84 & 182.03 & 48.5 \\
\hline & Beta Blockers & Metoprolol & 924 & 294.55 & 163.97 & 55.6 \\
\hline & & Sotalol & 79 & 449.50 & 237.60 & 52.8 \\
\hline & & Bisoprolol & 25439 & 299.56 & 189.60 & 63.3 \\
\hline & & Propranolol & 2327 & 231.78 & 91.58 & 39.5 \\
\hline & Angiotensin & Candesartan & 3467 & 685.66 & 309.54 & 45.1 \\
\hline & Receptor Blockers & s Valsartan & 15400 & 423.08 & 228.00 & 53.9 \\
\hline & & Ibersartan & 832 & 748.61 & 370.79 & 49.5 \\
\hline & & Telmisartan & 8213 & 930.47 & 411.6 & 44.2 \\
\hline & Calcium Blockers & Nifedipine & 2101 & 443.21 & 235.73 & 53.2 \\
\hline & & Diltiazem & 4207 & 569.33 & 316.28 & 55.5 \\
\hline & & Felodipine & 215 & 525.08 & 266.71 & 50.8 \\
\hline
\end{tabular}

In average, "me-too" drugs were $41.23 \%$ more expensive than classical treatment. The percentage covered by SS varied according to the medicines prescribed and it was in average $50.1 \%$ (range 37 to $68 \%$ ). The patients had to complete the amount of money remaining from their own pockets. Paradoxically, the percentage covered by SS for some "me-too" were greater than the percentage covered and paid for most classic medications of each group (table 1).
Analysing in detail any of the therapeutical groups it is clear that although the patients were treated mostly with the pioneer medicine, the few people that consumed "me-too" drugs, has spent the same o even more money than the majority of the patients treated (Figure 2).

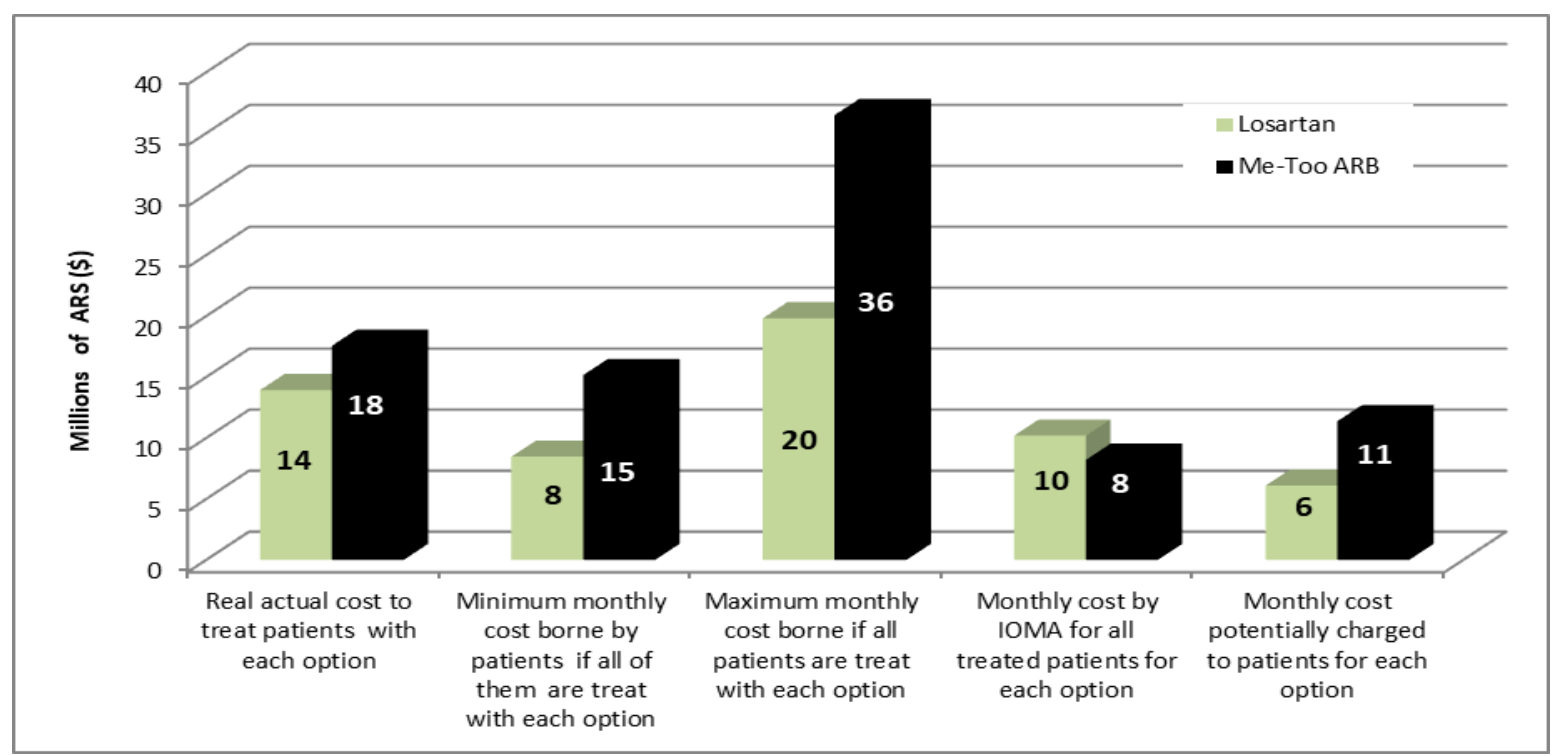

Figure 2: Cost analysis for hypertension treatment with angiotensin receptor blockers (ARB) 
By only choosing the drug of reference from each therapeutical group, the State Social Security could cover $100 \%$ of the cost of all anti-hypertensive treatment and all patients even saving almost 2 million dollars per year just by taking that decision (Figure 3).

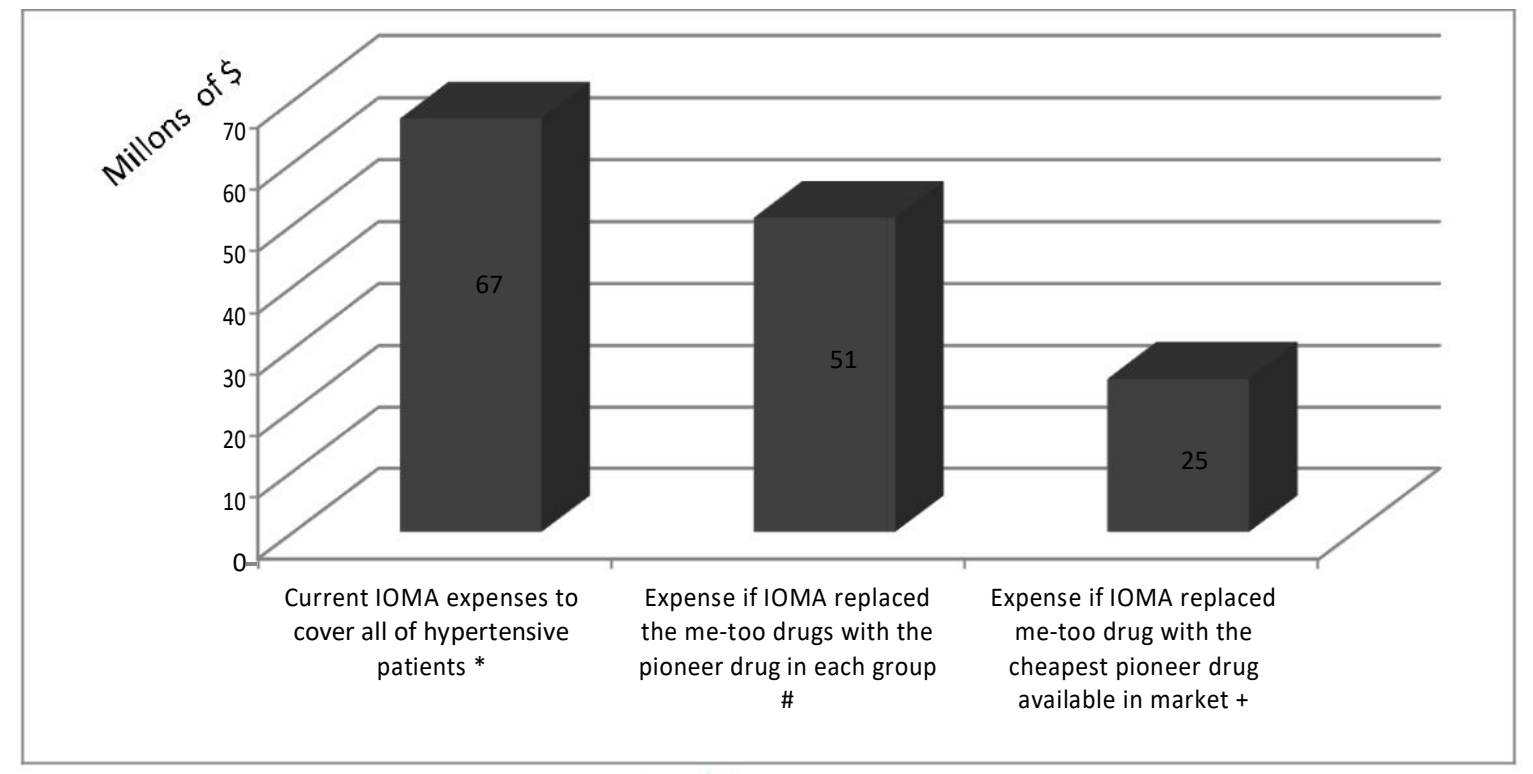

Figure 3: Market Price of Anti-Hypertensive Medications covered by SS-IOMA for the treatment of all patients (in millions of pesos)

* IOMA real expense to cover all of their hypertensive patients with the drug chosen considering their current prescriptions during the period of the study; \#Expense if IOMA replaced the me-too drug with the pioneer drug (average cost between existing commercial brands in the market) + For pioneer drug it exists several trade mark options in Argentinean market. This calculation is made taking into account the cheapest option in the market

\section{DISCUSION}

WHO stands for the rational use of medicines that includes recommendations in order to guarantee efficacy, safety, access and purchase of each drug at the lowest possible market price 9,10. It is logical to think that paying more for the same outcome is irrational.

It should be recognized that "me-too" drugs also demands many research and development resources from the pharmaceutical industries by creating these new products that mainly are not differentiated from pre-existing drugs; efforts that could be focus in more usefull task that requires ugent attention. 11.

So, if "me-too" drugs have the same mechanism of action and same outcomes that the pioneer/reference molecule of its therapeutical class group, it could be stand that the only goal of the pharmaceutical producers to develop molecules "metoo" is either to create additional costs of product, or to split the market with new drug options that has new brand patent that must be respected by the sanitary and commer-cial authorities of the countries 12 .

Noteworthy, it is still unclear why these "me-too" drugs are allowed to be registered in different countries while they do not add benefits except for the profitability for Pharmaceu-tical Industry of being marketed at a higher price than the preexisting equivalent drugs. And even more, why the health system and the Social Security are paying for these type of drugs, when there are well known options at a lower price?

It also should be discussed the fact that, although the profile of adverse effects are shared by all the drugs of a given therapeutic group, it is also true that side effects of the pioneer drugs are already well known by doctors and patients due the longest period of time that these drugs has been placed in the market, in relation to the "me-too " option 13. Is reasonable to accept then, that the new formula might have unexpected side effects that could expose patients to unnecessary risks.

Those authors that support the use of "me-too" drugs sustain that these products provide more therapeutic options and enhance competition 2. But why do we need new drugs of the same class and the same mechanism of action to do the same things and to get similar clinical outcomes, but at a much higher price?. It is true that some of the "me too" options have some kinetic characteristics that may provide longer duration of the effect, but that is not the rule 14 .

The results obtained in the present research demonstrate that by only replacing "me-too" drugs by the pioneer medicine, the Social Security of Buenos Aires (SS-IOMA) may increase the treatment coverage up to a $100 \%$ without additional ex-penses for patients, and even saving money from its budget.

The study also demonstrated that only $40 \%$ of the patients had adherence to treatment. Even if this topic is complexed and multi-factional 15, 16, and it is not an issue to be problematized in this paper, the data analysis lead us to think that if one of the causes that explains the lack of continuity in the treat-ments might be the pocket payment that patients must face, maybe if this payment obligation is exempted by installing a $100 \%$ coverage of the drugs by SS, then this percentage of adherence could be increased.

\section{CONCLUSION}

By taking the decision to replace "me-too" drugs for pioneer/ referral medicines it is possible to increase the Buenos Aires State Social Security treatment coverage from approximate-ly $50 \%$ to $100 \%$, avoiding the out-of-pocket payment by pa-tients; without affecting the quality of care or the outcome obtained from $t$ reatments of patients affected by arterial 
hypertension. Only considering the standard treatment for their hypertensive patients, even increasing the coverage up to $100 \%$, this measure allows obtaining a saving for the mentioned financier institution (SS) of almost two million dollars a year.

\section{REFERENCES}

1. Marin GH, Polach A. High-cost drugs: analysis and propos-als for the Mercosur countries. Rev Panam Salud Publica, 2011; 30(2):167-76

2. Jena AB, Calfee JE, Mansley EC, Philipson TJ. 'Me-Too' Innovation in Pharmaceutical Markets. Forum Health Econ Policy, 2009; 12(1) 5-10.

3. Correa CM. "Me-too medicines are new chemical entities developed for pharmaceutical use that do not include any genuine therapeutic improvement". In: Correa C. "Ownership of knowledge: the role of patents in pharmaceutical R\&D." Bull World Health Organ 2004; 82(10):785-6.

4. DiMasi JA. Price Trends for Prescription Pharmaceuticals: 1995-1999. Background report prepared for the U.S. Department of Health and Human Services' Conference on Pharmaceutical Pricing Practices, Utilization and Costs USG, Washington, D.C., USA, 2000.

5. Garattini S. Are me-too drugs justified? J Nephrol, 1997; 10(6):283-94.

6. diMasi J \& C Paquette. "The Economics of Follow-on Drug Research and Development Trends in Entry Rates and the
Timing of Development." Pharmacoeconomics, 2004; 22(2):114.

7. Kessler DA, Rose JL, Temple RJ, Schapiro R, Griffin JP. Therapeutic-Class Wars-Drug Promotion in a Competitive Marketplace. New Engl. J Med, 1994; 331(20):1350-3..

8. Calfee, J.E. Prices, Markets, and the Pharmaceutical Revolution. Washington DC: American Enterprise Institute Press, AEP, Washington, DC, USA, 2000.

9. Hogerzeil HV. Promoting Rational Prescribing: An International Perspective. British Journal of Clinical Pharmacology, 1995; 39:1-6.

10. Hogerzeil HV, et al. Field Tests for Rational Drug Use in Twelve Developing Countries. Lancet, 1993; 342:1408-1410.

11. Lee TH. "Me-Too" Products-Friend or Foe? New New Engl. J Med, 2004; 350(3):211-2.

12. Lichtenberg FR, Philipson TJ. The Dual Effects of Intellectual Property Regulations: Within- and between-Patent Competition in the U.S. Pharmaceuticals Industry. Journal of Law and Economics, 2002; 45:643-672.

13. Régnier $\mathrm{S}$. What is the value of 'me-too' drugs? Health Care Manag Sci, 2013; 16(4):300-313.

14. Marin GH, Canas M, Homar C, Perrotta M Drug utilization from Program REMEDIAR in Buenos Aires, Argentina. Latin America Journal of Pharmacy, 2008; 27:535-542.

15. Marin GH., Risso P., Sbatella D., Haag G.Treatment adherence by personalizing the drug dispensing for diabetic patients in social vulnerable situation .Quality in Primary Care, 2015; 23(2):93-96. 